\title{
Cardiac Malignant Peripheral Nerve Sheath Tumor
}

National Cancer Institute

\section{Source}

National Cancer Institute. Cardiac Malignant Peripheral Nerve Sheath Tumor. NCI

Thesaurus. Code C5367.

A very rare malignant peripheral nerve sheath tumor that arises from the heart. 